\title{
Case-Control Study of Inflammatory Bowel Disease Patients with and without Clostridium difficile Infection and Poor Outcomes in Patients Coinfected with C. difficile and Cytomegalovirus
}

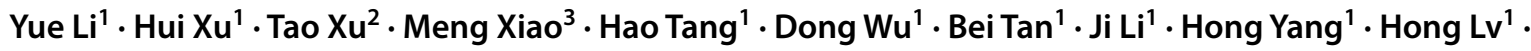 \\ Yingchun $\mathrm{Xu}^{3}$. Jiaming Qian ${ }^{1}$
}

Received: 4 January 2018 / Accepted: 30 July 2018 / Published online: 9 August 2018

(c) The Author(s) 2018

\begin{abstract}
Background and Aims Clostridium difficile infection (CDI) incidence and risk factors in patients with inflammatory bowel disease (IBD) have been extensively studied. However, data describing CDI in Chinese patients with IBD are limited. We investigated the cumulative incidence, risk factors, and outcomes of CDI in Chinese IBD patients.

Methods We conducted a retrospective, case-control study of patients hospitalized with IBD and CDI at Peking Union Medical College Hospital from January 2010 to December 2015. CDI was diagnosed based on the presence of active symptoms and positive enzyme immunoassay-based stool test results for $C$. difficile toxin A or B (CDAB). Controls were selected from $\mathrm{CDAB}$-negative patients with IBD and matched by age, gender, phenotypes of IBD and the same time period of CDAB testing at a $1: 2$ or $1: 3$ ratio.

Results We identified 60 (7.41\%) cases of CDI among 810 patients with IBD, and 137 control cases were selected. Univariate analysis revealed that IBD patients with CDI had higher rates of concurrent corticosteroid use, proton pump inhibitor, antibiotic use, recent hospitalization, parenteral nutrition support, and cytomegalovirus (CMV) coinfection $(P<0.05)$. Multivariate analysis revealed that concurrent corticosteroid use (odds ratio $[\mathrm{OR}]=6.803,95 \%$ confidence interval $[\mathrm{CI}]=2.901-15.954$, $P<0.001)$ and hospitalization within 1 month $(\mathrm{OR}=3.028,95 \% \mathrm{CI}=1.225-7.480, P=0.016)$ were associated with CDI. CMV and $C$. difficile coinfection (hazard ratio $[\mathrm{HR}]=4.185,95 \% \mathrm{CI}=1.492-11.736, P=0.007$ ) as well as disease severity (HR 2.070, 95\% CI = 1.006-4.261, $P=0.048$ ) were independently associated with colectomy following CDI.

Conclusions IBD patients with concurrent corticosteroid use and recent hospitalization are at a higher risk of CDI. CMV and $C$. difficile coinfection is associated with poorer outcomes.
\end{abstract}

Keywords Clostridium difficile · Risk factor · Inflammatory bowel disease · Crohn's disease · Ulcerative colitis · Cytomegalovirus $\cdot$ Colectomy

Yue $\mathrm{Li}$ and Hui Xu contributed equally to this study.

Jiaming Qian

qianjiaming1957@126.com

1 Department of Gastroenterology, Peking Union Medical College Hospital, Chinese Academy of Medical Sciences, Peking Union Medical College, No. 1 Shuaifuyuan, Dongcheng District, Beijing 100730, China

2 Department of Epidemiology and Biostatistics, Institute of Basic Medical Sciences, Chinese Academy of Medical Sciences, School of Basic Medicine, Peking Union Medical College, Beijing, China

3 Department of Clinical Laboratory, Peking Union Medical College Hospital, Chinese Academy of Medical Sciences, Peking Union Medical College, Beijing, China

$\begin{array}{ll}\text { Abbreviations } \\ \text { AUC } & \text { Area under the curve } \\ \text { CD } & \text { Crohn's disease } \\ \text { CDAB } & \text { C. difficile toxin A and B } \\ \text { CDI } & \text { C. difficile infection } \\ \text { CI } & \text { Confidence interval } \\ \text { CMV } & \text { Cytomegalovirus } \\ \text { EIA } & \text { Enzyme immunoassay } \\ \text { ELISA } & \text { Enzyme-linked immunosorbent assay } \\ \text { HR } & \text { Hazard ratio } \\ \text { IBD } & \text { Inflammatory bowel disease } \\ \text { IQR } & \text { Interquartile range } \\ \text { OR } & \text { Odds ratio } \\ \text { PCR } & \text { Polymerase chain reaction } \\ \text { PUMCH } & \text { Peking Union Medical College Hospital }\end{array}$




\section{UC Ulcerative colitis \\ ROC Receiver operating characteristic \\ 5-ASA 5-Aminosalicylates \\ 25(OH)D 25-Hydroxyvitamin D}

\section{Introduction}

Clostridium difficile ( $C$. difficile), a gram-positive sporeforming anaerobe, is the most commonly reported pathogen, causing $12.1 \%$ of healthcare-associated infections in the USA [1]. Studies have demonstrated an increasing incidence of $C$. difficile infection (CDI) in patients with inflammatory bowel disease (IBD) who commonly had a more severe course of disease than the non-IBD population [2-5]. Traditional risk factors for $\mathrm{CDI}$ include recent antibiotic use or hospital exposure, older age, comorbidity, immunosuppression, and underlying IBD [6]. However, CDI has been associated with certain risk factors, including younger age, colonic IBD, active colitis, community acquisition, and use of corticosteroids or infliximab, in patients with $\operatorname{IBD}[3,5$, 7]. In addition, $\mathrm{CDI}$ has been found to complicate the course of IBD and has been reported to be associated with poor prognosis, including increased colectomy, higher mortality, and longer length of hospital stay [7].

The exact epidemiology of CDI has been hindered by a lack of global reporting and surveillance programs. To date, there are limited data describing the epidemiology and prognosis of CDI in IBD patients in China $[8,9]$. One study reported that the incidence of CDI (19.3\%) in patients with ulcerative colitis (UC) was higher than that (12.7\%) in patients with Crohn's disease (CD) in South China [8]. The other retrospective study reported that CDI was diagnosed in 5\% (13 cases) of 260 patients with IBD in one tertiary hospital in Shanghai, China, from 2013 to 2015 [9]. The incidence, temporal change in incidence, risk factors, and prognosis of CDI in Chinese IBD patients are still poorly characterized. Therefore, we performed this study with the following aims: (1) to investigate the proportion of CDI for a longer duration and detect the temporal change in the proportion; (2) to identify the risk factors of CDI in patients with IBD; and (3) to explore the outcome of CDI in IBD patients.

\section{Patients and Methods}

\section{Patients}

This study was a retrospective, case-control study conducted at the Department of Gastroenterology, Peking Union Medical College Hospital (PUMCH). Hospitalized patients with IBD and CDI were identified from our hospital discharge database as well as central laboratory database between January 1,2010 , and December 31, 2015. The study population included patients with a discharge diagnosis of IBD, including UC, CD, or IBD unclassified (IBDU), and only patients who were hospitalized for an active disease. Enrolled patients $(n=60)$ were diagnosed with IBD and had a positive stool test for $C$. difficile toxin A or B (CDAB) by enzyme immunoassay (EIA). Each case was matched to 2 or 3 randomly selected CDAB-negative controls $(n=137)$ by IBD diagnosis, age, sex, and year of CDAB testing. The study was approved by Institutional Review Board of PUMCH. All data of the study were collected by reviewing preexisting records. No information from any individual patient was revealed, and all patient records were de-identified before being included in the present analysis. For these reasons, the study protocol was exempted from the need for informed consent from its participants.

\section{Study Measures and Outcomes}

CDI cases were defined as patients with active symptoms and a positive stool test for $C$. difficile toxin A or B by EIA (VIDAS ${ }^{\circledR} C$. difficile panel, BioMérieux, France).

Demographic characteristics included age, gender, smoking and drinking status. Clinical characteristics included the following: (1) clinical and epidemiological findings: age of IBD symptom onset, age of IBD diagnosis, duration from symptom onset to IBD diagnosis, age at CDI, duration of IBD at CDI, severity of UC by Truelove and Witts criteria [10], extent of UC (extensive colitis versus left-sided colitis or proctitis), Mayo endoscopic score of UC [11], Montreal classification of CD [12], Harvey-Bradshaw index for $\mathrm{CD}$ activity if documented in medical records [13], previous IBD-associated bowel surgery, diabetes comorbidity, body mass index, peripheral venous white blood cell count, hemoglobin, and plasma 25-hydroxyvitamin D [25(OH)D] before CDI; (2) potential risk factors of interest: simultaneous presence of CMV infection (diagnosis based on evidence of viral cytopathic effect by hematoxylin and eosin-stained tissue and/or the presence of any viral inclusion bodies by immunohistochemistry or in situ hybridization, or the presence of serum CMV-DNA > 500 copies/ml), recent (within 1 month) hospitalization for any reason, recent (within 3 and 1 month) use of antibiotics, recent (within 3 months) use of PPIs, recent (within 1 month) use of parenteral nutrition support, and concurrent use of 5-aminosalicylates (5-ASA), immunomodulators (including thiopurine, methotrexate, thalidomide), systemic corticosteroids, and anti-tumor necrosis factor (TNF)- $\alpha$ agent; and (3) outcome indicator: diseaserelated colectomy of any extent following the CDAB test.

In our clinical practice for patients with severe IBD episodes, stool $C$. difficile toxins, serum CMV-DNA, and detailed tissue diagnosis for CMV during colonoscopy are 
routinely performed on admission. The antiviral therapy was given as soon as the CMV infection was confirmed either by serum CMV or tissue diagnosis.

The primary outcomes of this study were the proportion of CDI in hospitalized IBD patients, the identification of risk factors associated with CDI, and the percentage of patients requiring colectomy after CDI for the clinical outcome study.

\section{Statistical Analysis}

Data were analyzed using SPSS for Windows version 21.0 (SPSS Inc., Chicago, IL, USA). Descriptive statistics were computed for all variables. Continuous variables were summarized using means and standard deviations or medians with 25th and 75th percentiles appropriately. Categorical variables were expressed in proportions. Univariate comparisons of continuous variables were conducted using $t$ tests or Wilcoxon rank-sum tests; univariate comparisons of categorical factors were conducted using Chi-square or Fisher's exact tests as appropriate. A multivariate logistic regression model using a forward stepwise selection method was constructed to study the possible risk factors of CDI. Data were reported as unadjusted odds ratios (ORs) with 95\% confidence intervals (CIs). $P$ values less than 0.05 were considered statistically significant. Surgery-free survival was determined with Kaplan-Meier analysis. Differences in bowel surgery rates were determined by log rank analysis and Cox regression. $P$ values less than 0.05 were considered statistically significant.

\section{Results}

\section{Epidemiology}

A total of 60 (7.41\%) CDI cases were identified from 810 hospitalized patients with active IBD. Patients with recurrent
CDI were not counted repeatedly in the proportion. Of 381 UC patients, 34 (8.92\%) tested positive for CDAB. Of 429 CD patients, 26 (6.06\%) were CDAB positive. The presumed incidence of CDI in hospitalized patients with IBD from 2010 to 2015 is listed in Table 1 . The incidence was lower than $2 \%$ in 2010 and gradually rose to over $12 \%$ in 2014. Figure 1 illustrates that, although it was not a steady increasing line, there was an increasing number of detected CDI cases in patients with IBD.

\section{Demographics and Characteristics}

The demographics and clinical characteristics of the study subjects (cases and controls) are listed in Table 2. The median duration of IBD (from disease onset to CDI) when CDI occurred was 29.5 (interquartile range [IQR] 7.0, 102.0) months. There was no difference found in smoking or drinking status, diabetes comorbidity, previous IBD-associated bowel surgery, body mass index, peripheral venous white blood cell count, hemoglobin, or plasma 25(OH)D between IBD patients with and without CDI $(P>0.05)$. Compared with patients without CDI, CD patients $(n=95)$ with CDI were more likely to be colon involved and had a higher

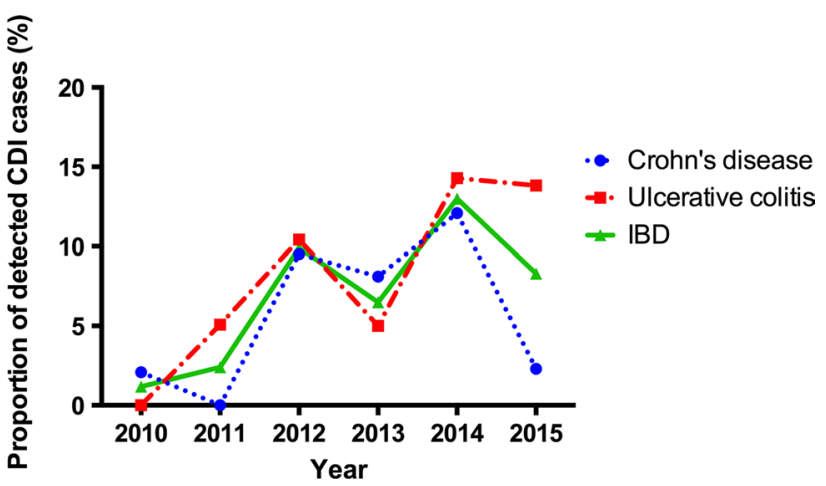

Fig. 1 Temporal trend of presumed incidence of CDI in hospitalized patients with IBD
Table 1 Presumed incidence of CDI in hospitalized patients with IBD

\begin{tabular}{llllllll}
\hline Year & 2010 & 2011 & 2012 & 2013 & 2014 & 2015 & Total \\
\hline CD with CDI & 1 & 0 & 6 & 6 & 11 & 2 & 26 \\
No. of CD patients & 48 & 66 & 63 & 74 & 91 & 87 & 429 \\
Presumed incidence (\%) & 2.08 & 0 & 9.52 & 8.11 & 12.09 & 2.3 & 6.06 \\
UC with CDI & 0 & 3 & 5 & 4 & 9 & 13 & 34 \\
No. of UC patients & 37 & 59 & 48 & 80 & 63 & 94 & 381 \\
Presumed incidence (\%) & 0 & 5.08 & 10.42 & 5.0 & 14.29 & 13.83 & 8.92 \\
CDI cases & 1 & 3 & 11 & 10 & 20 & 15 & 60 \\
IBD patients & 85 & 125 & 111 & 154 & 154 & 181 & 810 \\
Presumed incidence (\%) & 1.18 & 2.4 & 9.91 & 6.49 & 12.99 & 8.29 & 7.41 \\
\hline
\end{tabular}

$C D$ Crohn's disease, $C D I$ Clostridium difficile infection, $I B D$ inflammatory bowel disease, $U C$ ulcerative colitis 
Table 2 Demographics and clinical characteristics of IBD patients with and without CDI (with matched controls)

$$
\text { All }(n=197) \quad \text { CDAB positive }(n=60) \quad \text { CDAB negative }
$$

$$
(n=137)
$$

\begin{tabular}{|c|c|c|c|c|c|}
\hline \multicolumn{4}{|l|}{ Diagnosis } & \multirow[t]{3}{*}{0.826} & \multirow[t]{3}{*}{0.826} \\
\hline $\mathrm{CD}, n(\%)$ & $95(48.2 \%)$ & $26(43.3 \%)$ & $69(50.4 \%)$ & & \\
\hline $\mathrm{UC}, n(\%)$ & $102(51.8 \%)$ & $34(56.7 \%)$ & $68(49.6 \%)$ & & \\
\hline Median age of symptom onset, years (IQR) & $31.0(23.0,43.0)$ & $32.0(23.3,47.3)$ & $30.0(22.0,42.5)$ & $Z=-0.590$ & 0.556 \\
\hline Median age of IBD diagnosis, years, (IQR) & $34.0(25.0,46.0)$ & $35.0(27.0,47.5)$ & $33.0(25.0,45.5)$ & $Z=-0.469$ & 0.639 \\
\hline $\begin{array}{l}\text { Median duration from symptom onset to IBD } \\
\text { diagnosis, months, (IQR) }\end{array}$ & $12(4,48)$ & $6(3,36)$ & $13(5,48)$ & $Z=-1.520$ & 0.129 \\
\hline $\begin{array}{l}\text { Median age at time of CDAB testing, years, } \\
\text { (IQR) }\end{array}$ & $38.0(28.0,49.0)$ & $38.0(27.3,49.8)$ & $38.0(28.0,49.0)$ & $Z=-0.231$ & 0.817 \\
\hline Gender, male $n(\%)$ & $120(60.9 \%)$ & $3558.3 \%)$ & $85(62.0 \%)$ & 0.241 & 0.623 \\
\hline Smoking status, $n(\%)$ & & & & 0.247 & 0.884 \\
\hline Never & $149(75.6 \%)$ & $46(76.7 \%)$ & $103(75.2 \%)$ & & \\
\hline Current & $32(16.2 \%)$ & $10(16.7 \%)$ & $22(16.1 \%)$ & & \\
\hline Previous & $16(8.1 \%)$ & $4(6.7 \%)$ & $12(8.8 \%)$ & & \\
\hline Drinking status, $n(\%)$ & & & & 5.191 & 0.075 \\
\hline Never & $163(82.7 \%)$ & $47(78.3 \%)$ & $116(84.7 \%)$ & & \\
\hline Current & $14(7.1 \%)$ & $8(13.3 \%)$ & $6(4.4 \%)$ & & \\
\hline Previous & $20(10.2 \%)$ & $5(8.3 \%)$ & $15(10.9 \%)$ & & \\
\hline Diabetes comorbidity, $n(\%)$ & $13(6.6 \%)$ & $5(8.3 \%)$ & $8(5.8 \%)$ & 0.114 & 0.736 \\
\hline Previous IBD-associated bowel surgery, $n(\%)$ & $67(34.0 \%)$ & $17(28.3 \%)$ & $50(36.5 \%)$ & 1.239 & 0.266 \\
\hline $\mathrm{UC}$ & $5(4.9 \%)$ & $2(5.9 \%)$ & $3(4.4 \%)$ & 0.000 & 1.000 \\
\hline $\mathrm{CD}$ & $62(65.3 \%)$ & $15(57.7 \%)$ & $47(68.1 \%)$ & 0.905 & 0.341 \\
\hline Body mass index, mean $\pm \mathrm{SD}$ & $20.0 \pm 3.7(n=192)$ & $19.4 \pm 3.3(n=55)$ & $20.3 \pm 3.8(\mathrm{n}=137)$ & $\mathrm{t}=1.368$ & 0.168 \\
\hline $\begin{array}{l}\text { Hemoglobin }(\mathrm{g} / \mathrm{L}) \text { at time of CDAB testing, } \\
\text { mean } \pm \mathrm{SD}\end{array}$ & $111.7 \pm 23.8$ & $107.3 \pm 23.7$ & $113.6 \pm 23.6$ & $\mathrm{t}=1.699$ & 0.091 \\
\hline $\begin{array}{l}\text { Peripheral venous white blood cell count } \\
\left(10^{9} / \mathrm{L}\right) \text {, mean } \pm \mathrm{SD}\end{array}$ & $7.44 \pm 3.06$ & $7.90 \pm 2.94$ & $7.24 \pm 3.10$ & $\mathrm{t}=1.433$ & 0.154 \\
\hline Plasma 25(OH)D $(\mu \mathrm{g} / \mathrm{L})$, mean $\pm \mathrm{SD}$ & $13.8 \pm 8.4(\mathrm{n}=117)$ & $13.5 \pm 7.1(\mathrm{n}=31)$ & $14.0 \pm 8.9(n=86)$ & $\mathrm{t}=-0.250$ & 0.803 \\
\hline $\mathrm{UC}$ & $11.2 \pm 6.4^{*}(\mathrm{n}=57)$ & $10.8 \pm 5.9(n=15)$ & $11.4 \pm 6.7(n=42)$ & $\mathrm{t}=0.314$ & 0.755 \\
\hline $\mathrm{CD}$ & $16.3 \pm 9.3(n=60)$ & $16.1 \pm 7.3(n=16)$ & $16.4 \pm 10.0(n=44)$ & $\mathrm{t}=0.119$ & 0.906 \\
\hline $\mathrm{CD}$ & $n=95$ & $n=26$ & $n=69$ & & \\
\hline
\end{tabular}

Disease phenotype

Montreal classification, Age, $n(\%)$

$\mathrm{A} 1: \leq 16$ years old

A2: $17-40$ years old

A3: $\geq 40$ years old

Montreal classification, location, $\mathrm{n}(\%)$

L1: terminal ileum

L2: colon

L3: ileum-colon

L4: upper GI tract

Montreal classification, behavior, $n(\%)$

B1: non-stricturing, non-penetrating

B2: stricturing

B3: penetrating

Perianal disease, $\mathrm{n}(\%)$

Harvey-Bradshaw index, median (IQR)

\begin{tabular}{|c|c|c|c|c|}
\hline $7(7.4 \%)$ & $2(7.7 \%)$ & $5(7.2 \%)$ & & \\
\hline $70(73.7 \%)$ & $21(80.8 \%)$ & $49(71.0 \%)$ & & \\
\hline \multirow[t]{2}{*}{$18(18.9 \%)$} & $3(11.5 \%)$ & $15(21.7 \%)$ & & \\
\hline & & & Fisher & 0.003 \\
\hline $9(9.5 \%)$ & $6(23.1 \%)$ & $3(4.3 \%)$ & & \\
\hline $13(13.7 \%)$ & $6(23.1 \%)$ & $7(10.1 \%)$ & & \\
\hline $73(76.8 \%)$ & $14(53.8 \%)$ & $59(85.5 \%)$ & & \\
\hline \multirow[t]{2}{*}{$55.3 \%)$} & $3(11.5 \%)$ & $2(2.9 \%)$ & 1.360 & 0.244 \\
\hline & & & 0.965 & 0.617 \\
\hline $23(24.2 \%)$ & $7(26.9 \%)$ & $16(23.2 \%)$ & & \\
\hline $33(34.7 \%)$ & 7 (26.9\%) & $26(37.7 \%)$ & & \\
\hline $39(41.1 \%)$ & $12(46.2 \%)$ & $27(39.1 \%)$ & & \\
\hline $33(34.7 \%)$ & $7(26.9 \%)$ & $26(37.7 \%)$ & 0.964 & 0.326 \\
\hline $6(4,8)$ & $7(6,10)$ & $6(3,9)$ & $Z=2.474$ & 0.013 \\
\hline
\end{tabular}

Fisher $\quad 0.527$ 
Table 2 (continued)

\begin{tabular}{|c|c|c|c|c|c|}
\hline UC & $n=102$ & $n=34$ & $n=68$ & & \\
\hline \multicolumn{4}{|l|}{ Severity by Truelove and Witts criteria, $n(\%)$} & 2.795 & 0.247 \\
\hline Mild & $17(16.7 \%)$ & $3(8.8 \%)$ & $14(20.6 \%)$ & & \\
\hline Moderate & $45(44.1 \%)$ & $18(52.9 \%)$ & $27(39.7 \%)$ & & \\
\hline Severe & $40(39.2 \%)$ & $13(38.2 \%)$ & $27(39.7 \%)$ & & \\
\hline Mayo endoscopic subscore, $n(\%)$ & $n=97$ & $n=32$ & $n=65$ & 1.729 & 0.630 \\
\hline 1 & $13(13.4 \%)$ & $5(15.6 \%)$ & $8(12.3 \%)$ & & \\
\hline 2 & $38(39.2 \%)$ & $10(31.3 \%)$ & $28(43.1 \%)$ & & \\
\hline 3 & $46(47.4 \%)$ & $17(53.1 \%)$ & $29(44.6 \%)$ & & \\
\hline \multicolumn{4}{|l|}{ Disease extent, $n(\%)$} & 2.207 & 0.363 \\
\hline Proctitis & $1(1.0 \%)$ & $1(2.9 \%)$ & 0 & & \\
\hline Left-sided colitis & $25(24.5 \%)$ & $8(23.5 \%)$ & $17(25.0 \%)$ & & \\
\hline Extensive colitis & $76(74.5 \%)$ & $25(73.5 \%)$ & $51(75.0 \%)$ & & \\
\hline \multicolumn{6}{|l|}{ Treatment outcome } \\
\hline Colectomy following CDI, $n(\%)$ & $27(13.7 \%)$ & $12(20.0 \%)$ & $15(10.9 \%)$ & 2.890 & 0.089 \\
\hline $\begin{array}{l}\text { Colectomy following CDI in patients with } \mathrm{UC} \text {, } \\
n(\%)\end{array}$ & $18(17.6 \%)$ & $8(23.5 \%)$ & $10(14.7 \%)$ & 1.214 & 0.270 \\
\hline $\begin{array}{l}\text { Colectomy following CDI in patients with } \mathrm{CD} \text {, } \\
n(\%)\end{array}$ & $9(9.5 \%)$ & $4(15.4 \%)$ & $5(7.2 \%)$ & 0.664 & 0.415 \\
\hline $\begin{array}{l}\text { Duration from CDAB testing to colectomy } \\
\text { (month), median (IQR) }\end{array}$ & $2.0(0.8,6.3)$ & $4.3(0.7,12.5)$ & $1.0(0.7,3.0)$ & & 0.449 \\
\hline
\end{tabular}

$C D$ Crohn's disease, $C D I$ Clostridium difficile infection, $C D A B C$. difficile toxin A and $\mathrm{B}, C M V$ cytomegalovirus, IBD inflammatory bowel disease, $I Q R$ interquartile range, $U C$ ulcerative colitis, $T N F$ tumor necrosis factor

Harvey-Bradshaw index $(P=0.003$ and 0.013 , respectively). In UC patients $(n=102)$, there was no difference in disease severity, Mayo endoscopic subscore, or disease extent between patients with and without CDI $(P>0.05)$.

Of the 60 patients with CDI, $50(83.3 \%)$ had a colonoscopy within 1 week before or after the diagnosis of CDI. The presence of pseudo-membranes was found in only 2 (6.3\%) out of 32 patients with UC (Fig. 2), whereas colonoscopy results revealed that these pseudo-membranous features were absent from all of the 18 patients with $\mathrm{CD}$ and CDI.

\section{Risk Factors for CDI}

As shown in Table 3, univariate analysis revealed that IBD patients with CDI had a higher rate of concurrent use of corticosteroids, use of antibiotics and PPIs within 3 months
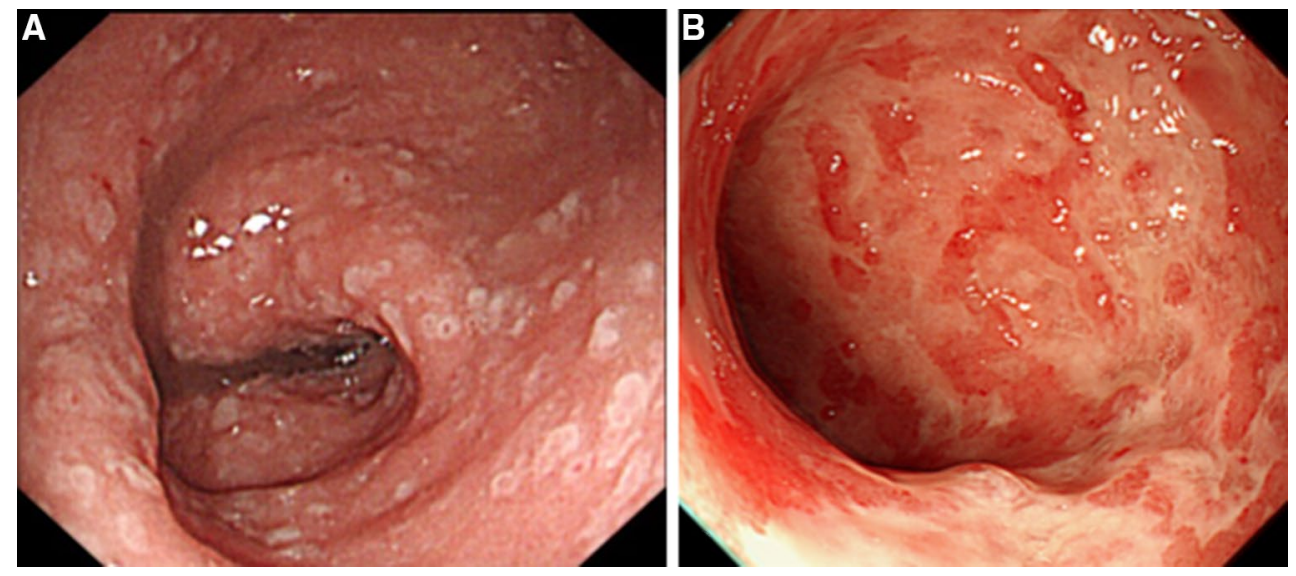

Fig. 2 Endoscopic features of patients with IBD and CDI. a Pseudo-membrane was discovered in this patient with UC and CDI. b Colonoscopic appearance of a patient with UC coinfected with both $C$. difficile and CMV colitis (diagnosed by immunohistochemistry) 
Table 3 Risk factors of Clostridium difficile infection

\begin{tabular}{|c|c|c|c|c|c|c|c|}
\hline Risk factors & All $(n=197)$ & $\begin{array}{l}\text { CDAB positive } \\
(n=60)\end{array}$ & $\begin{array}{l}\text { CDAB negative } \\
(n=137)\end{array}$ & & $\begin{array}{l}P \text { value of } \\
\text { univariate } \\
\text { analysis }\end{array}$ & $\begin{array}{l}\text { Odds ratio }(95 \% \\
\text { CI) }\end{array}$ & $\begin{array}{l}P \text { value of } \\
\text { multivariate } \\
\text { analysis }\end{array}$ \\
\hline $\begin{array}{l}\text { Concurrent use of } \\
\text { 5-ASA, } n(\%)\end{array}$ & $140(71.1 \%)$ & $46(76.7 \%)$ & $94(68.6 \%)$ & 1.316 & 0.251 & & \\
\hline $\begin{array}{l}\text { Concurrent use of } \\
\text { corticosteroids, } \\
n(\%)\end{array}$ & $101(51.3 \%)$ & $51(85.0 \%)$ & $50(36.5 \%)$ & 39.291 & $<0.001$ & $\begin{array}{l}6.803(2.901- \\
15.954)\end{array}$ & $<0.001$ \\
\hline $\begin{array}{l}\text { Dosage of corti- } \\
\text { costeroids, mg/ } \\
\text { day, median } \\
\text { (IQR) }\end{array}$ & $40.0(28.75,50.0)$ & $45.0(40.0,50.0)$ & $\begin{array}{l}30.0(18.75 \\
46.25)\end{array}$ & $Z=-3.771$ & $<0.001$ & & \\
\hline $\begin{array}{l}\text { Concurrent use of } \\
\text { immunomodula- } \\
\text { tors, } n(\%)\end{array}$ & $35(17.8 \%)$ & $8(13.3 \%)$ & $27(19.7 \%)$ & 1.161 & 0.281 & & \\
\hline $\begin{array}{l}\text { Concurrent use of } \\
\text { anti-TNF, } n(\%)\end{array}$ & $13(6.6 \%)$ & $6(10.0 \%)$ & $7(5.1 \%)$ & 0.923 & 0.203 & & \\
\hline $\begin{array}{l}\text { Antibiotics use } \\
\text { within } 3 \text { months } \\
\text { prior to CDI, } \\
n(\%)\end{array}$ & & & & 9.864 & 0.007 & $\begin{array}{l}1.258(0.386- \\
4.098)\end{array}$ & 0.703 \\
\hline Yes & $39(19.8 \%)$ & $19(31.7 \%)$ & $20(14.6 \%)$ & & & & \\
\hline Unknown & $23(11.7 \%)$ & $9(15.0 \%)$ & $14(10.2 \%)$ & & & & \\
\hline $\begin{array}{l}\text { Antibiotics use } \\
\text { within } 1 \text { month } \\
\text { prior to CDI, } \\
n(\%)\end{array}$ & & & & 2.082 & 0.353 & & \\
\hline Yes & $58(29.4 \%)$ & $21(35.0 \%)$ & $37(27.0 \%)$ & & & & \\
\hline Unknown & $22(11.2 \%)$ & $7(11.7 \%)$ & $15(10.9 \%)$ & & & & \\
\hline $\begin{array}{l}\text { PPI use within } \\
3 \text { months prior } \\
\text { to CDI, } n(\%)\end{array}$ & & & & 10.459 & 0.005 & $\begin{array}{l}0.432(0.121- \\
1.535)\end{array}$ & 0.194 \\
\hline Yes & $21(10.7 \%)$ & $12(20.0 \%)$ & $9(6.6 \%)$ & & & & \\
\hline Unknown & $40(20.3 \%)$ & $15(25.0 \%)$ & $25(18.2 \%)$ & & & & \\
\hline $\begin{array}{l}\text { Parenteral nutri- } \\
\text { tion support } \\
\text { within } 1 \text { month } \\
\text { prior to CDI, } \\
n(\%)\end{array}$ & & & & 14.109 & 0.001 & $\begin{array}{l}1.985(0.435- \\
9.064)\end{array}$ & 0.376 \\
\hline Yes & $35(17.8 \%)$ & $18(30.0 \%)$ & $17(12.4 \%)$ & & & & \\
\hline Unknown & $24(12.2 \%)$ & $11(18.3 \%)$ & $13(9.5 \%)$ & & & & \\
\hline $\begin{array}{l}\text { Hospitalization } \\
\text { within } 1 \text { month } \\
\text { prior to CDI, } \\
n(\%)\end{array}$ & $83(42.1 \%)$ & $41(68.3 \%)$ & $42(30.7 \%)$ & 24.294 & $<0.001$ & $\begin{array}{l}3.028(1.225- \\
7.480)\end{array}$ & 0.016 \\
\hline $\begin{array}{l}\text { Concomitant } \\
\text { CMV infection, } \\
n(\%)\end{array}$ & $28(14.2 \%)$ & $18(30.0 \%)$ & $10(7.3 \%)$ & 17.635 & $<0.001$ & $\begin{array}{l}1.788(0.637- \\
5.020)\end{array}$ & 0.270 \\
\hline $\begin{array}{l}\text { CMV infection } \\
\text { in patients with } \\
\text { UC, } n(\%)\end{array}$ & $26(25.5 \%)$ & $16(47.1 \%)$ & $10(14.7 \%)$ & 12.492 & 0.001 & & \\
\hline $\begin{array}{l}\text { CMV infection } \\
\text { in patients with } \\
\text { CD, } n(\%)\end{array}$ & $2(2.1 \%)$ & $2(7.7 \%)$ & 0 & Fisher & 0.029 & & \\
\hline
\end{tabular}

$C D$ Crohn's disease, $U C$ ulcerative colitis, $C D I$ Clostridium difficile infection, $C D A B C$. difficile toxin A and $\mathrm{B}, C M V$ cytomegalovirus, $I B D$ inflammatory bowel disease, $I Q R$ interquartile range, $T N F$ tumor necrosis factor 
prior to CDI, recent hospitalization within 1 month for any reason, parenteral nutrition support within 1 month prior to $\mathrm{CDI}$, and concomitant cytomegalovirus (CMV) coinfection than patients without CDI $(P<0.05)$. CMV infection was more common in IBD patients with CDI than that in patients without CDI ( 30.0 vs $7.3 \%, P<0.001)$. However, the concurrent use of immunomodulators, anti-TNF agents, 5-ASA, and antibiotics within 1 month prior to CDI were not found to be associated with CDI $(P>0.05)$.

Logistic regression analysis (Table 3 ) showed that the concurrent use of corticosteroids $(\mathrm{OR}=6.803,95 \% \mathrm{CI}$, 2.901-15.954, $P<0.001)$ and hospitalization within 1 month prior to $\mathrm{CDI}(\mathrm{OR}=3.028,95 \% \mathrm{CI} 1.225-7.480, P=0.016)$ were associated with CDI. Receiver operating characteristic (ROC) curve (Fig. 3) analysis showed that the dosage of corticosteroids that equaled prednisone $37.5 \mathrm{mg} / \mathrm{day}$ was the cutoff value for association with CDI (area under curve $[\mathrm{AUC}]=0.75$ ).

\section{Treatment Outcome}

CDI patients were prescribed metronidazole $(n=39)$, vancomycin $(n=16)$, or combined therapy $(n=5)$ at the physicians' discretion. Median treatment duration was 14 (range
8-16) days. Of the $60 \mathrm{CDI}$ patients, $6(10 \%)$ had recurrent CDI after a median of 2.3 (IQR 1.0, 4.5) months from the first episode of CDI. Among the 18 patients with CDI and CMV coinfection, 14 cases received antiviral therapy by ganciclovir and 1 case by foscarnet sodium on physicians' discretion. As illustrated in Table 2, the rate of diseaserelated colectomy following CDI was higher in patients with CDI than that in controls but with no significance (20.2 vs $10.9 \%, P=0.089)$. The median duration from CDI to colectomy was 4.3 (IQR $0.7,12.5$ ) months. Cox regression analysis (Table 4) revealed that CMV coinfection (hazard ratio $[\mathrm{HR}]=4.185,95 \%$ CI $1.492-11.736, P=0.007)$ and disease severity $(\mathrm{HR}=2.070,95 \% \mathrm{CI} 1.006-4.261, P=0.048)$ were independently associated with colectomy following CDI in patients with IBD.

\section{Discussion}

CDI in patients with IBD has been recognized as an essential clinical problem due to the growing incidence, increasing prevalence, and worsening outcome. IBD is proven to be an independent risk factor of CDI. A population-based study revealed that individuals with IBD were approximately five
A

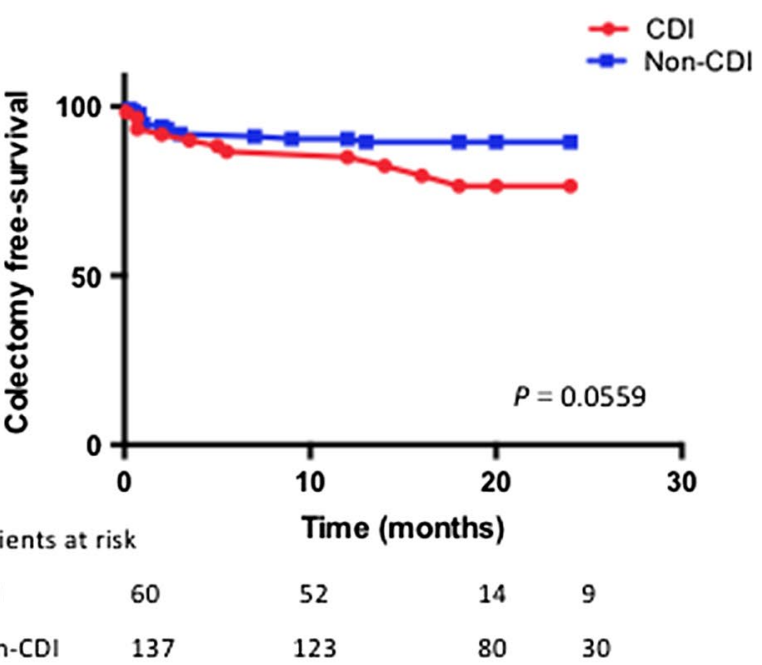

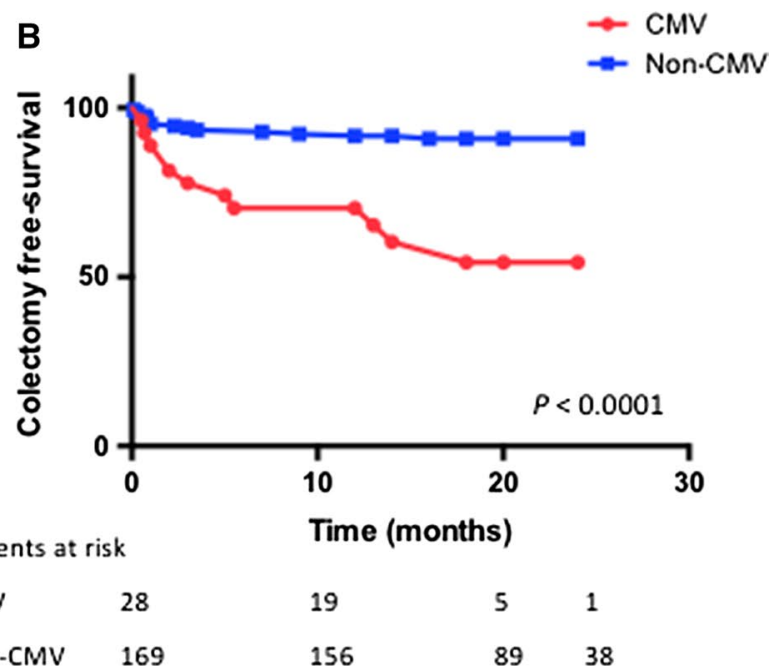

Fig. 3 Kaplan-Meier curve for colectomy-free survival in patients with IBD. a Colectomy-free survival for patients with and without CDI. b Colectomy-free survival for patients with and without CMV coinfection

Table 4 Risk factors of bowel surgery after CDI by Cox regression

\begin{tabular}{lllll}
\hline & Reference & Hazard ratio & $95 \%$ CI & $P$ value \\
\hline CDI & Yes versus no & 1.091 & $0.465-2.558$ & 0.841 \\
Diagnosis of IBD & UC versus CD & 0.529 & $0.167-1.680$ & 0.280 \\
CMV coinfection & Yes versus no & 4.185 & $1.492-11.736$ & 0.007 \\
Disease severity & $\begin{array}{l}\text { Severe versus mild and } \\
\text { moderate }\end{array}$ & 2.070 & $1.006-4.261$ & 0.048 \\
& & & \\
\hline
\end{tabular}

$C D$ Crohn's disease, $U C$ ulcerative colitis, $C D I$ Clostridium difficile infection, $C M V$ cytomegalovirus 
times more likely to develop CDI than individuals without IBD [5]. In the present study, we have shown the following: (1) CDI cases and its proportion in hospitalized IBD patients are increasing in our tertiary IBD center in recent years; (2) the use of steroids and recent (within 1 month) hospitalization are associated with CDI; and (3) CMV coinfection is independently associated with IBD-related colectomy after CDI in IBD patients.

The presumed incidence CDI in hospitalized patients with IBD at our center has increased from $1.18 \%$ in 2010 to $8.29 \%$ in 2015 , and the highest number $(12.99 \%)$ occurred in 2014. The prevalence of CDI is $7.41 \%$ in our tertiary IBD center. Most studies reported the prevalence of CDI in hospitalized IBD patients ranging from 1 to $10 \%$ [2-4, 14]. Furthermore, several studies from single centers reported in $2007[15,16]$ and studies using national hospitalization databases reported in 2008 [2,14] have shown a temporal increase in the proportion of IBD hospitalizations complicated by CDI. A nationwide temporal increase in CDI in IBD hospitalizations from 1998 to 2007 was reported [4]. Although two studies have reported the prevalence of CDI in Chinese IBD patients, our present study is the first to show the temporal change in the proportion of CDI in hospitalized IBD patients. Due to the retrospective nature of this study, we have no data on the percentage of patients underwent testing for $C$. difficile toxin each year. Bias from physicians' awareness was introduced in this study. In 2012, the publication of Chinese consensus on IBD management which emphasized opportunistic infection screening may explain the prominent increase of incidence from 2012. A more recent study describing the incidence of CDI in IBD patients found a decreasing trend [17]. In the UK, the incidence of CDI in IBD patients decreased from $8.7 \%$ in 2007/2008 to $0.4 \%$ in 2012/2013 [17]. Potential explanations for these observations are as follows: (1) better and prompt management of IBD in recent years, i.e., the early introduction of anti-TNF $\alpha$ agents to improve mucosal function and thereby reduce $C$. difficile colonization and (2) improved awareness of CDI and infection control practices in healthcare providers. In our study, we also observed a decrease in the proportion of detected CDI cases between 2014 (12.99\%) and 2015 (8.29\%). Ongoing monitoring of the temporal changes will reveal whether China exhibits a trend of CDI incidence similar to the recent study from the UK.

Endoscopy rarely detects pseudo-membranes and is therefore ineffective at diagnosing CDI in patients with $\operatorname{IBD}[15,18]$. It was reported that endoscopic pseudo-membranes were found in $13 \%$ of patients with IBD and CDI and that these patients more commonly presented with fever $(P=0.02)$ than patients without pseudo-membranes [19]. In our study, fewer endoscopic pseudo-membranes were found, with $6.3 \%$ in patients with UC and CDI and $0 \%$ in patients with $\mathrm{CD}$ and CDI. Therefore, the diagnosis of CDI is predominantly based on $C$. difficile toxin tests. The CDI diagnostic conundrum has been resolved by the development of molecular assays for toxigenic $C$. difficile that utilize real-time PCR to detect the $t c d B$ gene encoding toxin B in fecal specimens, and these new assays have a higher sensitivity and specificity than the conventional enzyme-linked immunosorbent assay (ELISA)-based assays [20, 21]. Given the relatively lower sensitivity of ELISA-based assays, the incidence and prevalence of CDI reported in our study may be underestimated.

Which IBD patients are at the greatest risk of acquiring C. difficile infection? Risk factors for CDI in patients with IBD are different from those of non-IBD patients, such as younger age and fewer predisposing non-IBD-related comorbidities [2, 14]. Moreover, risk factors for CDI in non-IBD patients, such as antibiotic use or PPI use, are less common in patients with IBD [15]. Consistent with the known epidemiology of CDI in patients with IBD, our study found that recent hospitalization or use of steroids remained one of the strongest risk factors for CDI. Data from IBD cohorts did not consistently demonstrate the independent associations between medication use (including immunomodulators, anti-TNF agents, and 5-ASA) and risk of CDI [15], and our findings confirmed this lack of association. In a population-based IBD cohort from British Columbia, the use of corticosteroids tripled the risk of CDI in a manner that was independent of dose or duration [22]. However, in our study, we found a higher risk of CDI in patients administered a dosage of prednisone over $37.5 \mathrm{mg} /$ day.

Higher plasma calcifediol $[25(\mathrm{OH}) \mathrm{D}]$ was found to be associated with reduced risk of $C$. difficile infection in patients with IBD [23]. This study suggested a role for vitamin D in the pathogenesis of CDI in patients with IBD. Vitamin D stimulates the production of cathelicidin, which is an antimicrobial peptide that is widely expressed in neutrophils, natural killer cells, and intestinal epithelium, and has antibacterial activity against a spectrum of bacterial pathogens [24]. Furthermore, it was recently reported that cathelicidin inhibits the effect of $C$. difficile toxin [25]. However, our study did not find an association between plasma $25(\mathrm{OH})$ $D$ levels and the risk of CDI. However, because only half $(n=31)$ of the patients with CDI had available $25(\mathrm{OH}) \mathrm{D}$ levels prior to CDI, the small sample size may weaken the power of this finding. Further studies investigating the association between $25(\mathrm{OH}) \mathrm{D}$ and the risk of $\mathrm{CDI}$ as well as the role of vitamin $\mathrm{D}$ adjunctive treatment in IBD patients to reduce the risk of CDI are imperative.

CDI was reported to worsen the outcome of patients with IBD and was associated with mortality, colectomy, and health resource utilization $[2,7,8,15]$. However, studies reporting the impact of CDI on the risk of colectomy are inconsistent. Some single-center and nationwide studies failed to find an association between colectomy following 
CDI $[2,26]$. Our study added evidence of no association between CDI alone and the subsequent colectomy. However, we found that the occurrence of CDI and CMV coinfections in patients strongly associated with the subsequent colectomy. We also found that CMV infection was more common in IBD patients with CDI. A recent study reported that CDI occurred more frequently in IBD patients with CMV reactivation and was associated with poor outcomes [27]. Conversely, our study revealed a higher rate of CMV coinfection in IBD patients with CDI and the association with poorer outcomes. A review article reported clinical scenario of coexisting cytomegalovirus infection in immunocompetent patients with CDI [28]. In cases of coexisting CMV and $C$. difficile colitis, ganciclovir therapy for CMV colitis in time may circumvent the unnecessary second-line therapeutic method for CDI, supposing that persistent diarrhea was not due to treatment failure for $C$. difficile [28]. In our clinical practice, coinfection is mostly seen in severe patients or those who received consequent or joined immunosuppressive medications. The severity of IBD itself may also contribute to the vulnerability of coinfections and poorer outcome. Although most of IBD patients with CDI-CMV coinfections were treated with antiviral therapy (15/18), but mostly the outcome of colectomy was still not prevented. Delayed diagnosis or initiation of antiviral therapy may not be the reason for poor outcome. Other more aggressive, novel, or adjunctive therapy such as using fecal microbiota transplantation, fidaxomicin, and anti-CMV immunoglobulin may need further investigation. Being aware of the poor outcomes of patients with coinfections, physicians should promptly test and aggressively manage these high-risk patients.

There are strengths in our study. First, to our knowledge, this is the first study in China and even in Asia to demonstrate a temporal change in $C$. difficile infection in patients with IBD. Second, the case-control study design restricts bias commonly seen in a retrospective study. For instance, matching for age restricts the age-related bias. Matching for IBD subtype reduces bias associated with different risks of CDI and IBD type. Matching for sample test period further controls for temporal changes in the overall incidence of CDI. Third, most patients in our cohort were regularly monitored at our center, which further increased the strengths of the outcome evaluation.

Despite the strengths, several limitations and weakness should be considered. First, since our cohorts were recruited from a tertiary referral center, the study results may not be generalized to the IBD population. Second, the findings are based on a small sample size due to the retrospective nature of this study. Third, given the relatively lower sensitivity of the EIA-based CDAB test, the rate of CDI may possibly be underestimated. Fourth, we did not present the proportion of IBD patients who were tested for CDI and CMV colitis each year. An increasing proportion of tests in IBD patients due to physicians' awareness may cause bias to the study findings. Fifth, the study controls were initially planned as $1: 3$, while in most cases only 1:2 controls were qualified. Finally, we did not assess the strain of $C$. difficile in patients with CDI.

In conclusion, the occurrence of CDI is increasing in Chinese IBD patients. Patients with a higher dose of corticosteroids and recent hospitalization have a higher risk of CDI, and coinfection of CMV and CDI results in a poorer outcome, even antiviral therapy was mostly given in time. We believe this study will remind physicians of the importance of testing for $C$. difficile and CMV when providing care for patients admitted for active IBD. Due to the increasing incidence of CDI, infection control should be emphasized in China. Aggressive management including other potential strategies should be considered for IBD patients with coinfections, which might need further studies to confirm. Further studies are needed to confirm our results.

Author's contribution YL: acquisition of data, analysis and interpretation of data, drafting of the manuscript and statistical analysis; HX: acquisition of data and analysis and interpretation of data; TX: analysis of data and statistical analysis; MX, HT, DW, BT, JL, HY, and HL: acquisition of data; JQ, and YX: study concept and design, critical revision of the manuscript for important intellectual content, and study supervision.

Funding The funding was provided by CAMS Initiative for Innovative Medicine (Grand No. 2017-I2 M-3-017) and The Education Reform Projects of Peking Union Medical College (Grand No. 2015zlgc0706).

\section{Compliance with ethical standards}

Conflict of interest The authors have no conflicts of interest to report.

Open Access This article is distributed under the terms of the Creative Commons Attribution-NonCommercial 4.0 International License (http://creativecommons.org/licenses/by-nc/4.0/), which permits any noncommercial use, distribution, and reproduction in any medium, provided you give appropriate credit to the original author(s) and the source, provide a link to the Creative Commons license, and indicate if changes were made.

\section{References}

1. Magill SS, Edwards JR, Bamberg W, et al. Multistate pointprevalence survey of health care-associated infections. $N$ Engl J Med. 2014;370:1198-1208.

2. Nguyen GC, Kaplan GG, Harris ML, Brant SR. A national survey of the prevalence and impact of Clostridium difficile infection among hospitalized inflammatory bowel disease patients. Am J Gastroenterol. 2008;103:1443-1450.

3. Ananthakrishnan AN, Issa M, Binion DG. Clostridium difficile and inflammatory bowel disease. Gastroenterol Clin N Am. 2009;38:711-728.

4. Ananthakrishnan AN, McGinley EL, Saeian K, Binion DG. Temporal trends in disease outcomes related to Clostridium 
difficile infection in patients with inflammatory bowel disease. Inflamm Bowel Dis. 2011;17:976-983.

5. Singh H, Nugent Z, Yu BN, Lix LM, Targownik LE, Bernstein $\mathrm{CN}$. Higher incidence of Clostridium difficile Infection among individuals with inflammatory bowel disease. Gastroenterology. 2017; 153:430-8.e2.

6. Leffler DA, Lamont JT. Clostridium difficile infection. $N$ Engl J Med. 2015;372:1539-1548.

7. Berg AM, Kelly CP, Farraye FA. Clostridium difficile infection in the inflammatory bowel disease patient. Inflamm Bowel Dis. 2013;19:194-204.

8. Zhang T, Lin QY, Fei JX, et al. Clostridium difficile infection worsen outcome of hospitalized patients with inflammatory bowel disease. Sci Rep. 2016;6:29791.

9. Gu YB, Zhang MC, Sun J, Lv KZ, Zhong J. Risk factors and clinical outcome of Clostridium difficile infection in patients with IBD: a single-center retrospective study of 260 cases in China. $J$ Dig Dis. 2017;18:207-211.

10. Truelove SC, Witts LJ. Cortisone in ulcerative colitis; final report on a therapeutic trial. Br Med J. 1955;2:1041-1048.

11. Schroeder KW, Tremaine WJ, Ilstrup DM. Coated oral 5-aminosalicylic acid therapy for mildly to moderately active ulcerative colitis. A randomized study. $N$ Engl J Med. 1987;317:1625-1629.

12. Silverberg, Satsangi J, Ahmad T, et al. Toward an integrated clinical, molecular and serological classification of inflammatory bowel disease: report of a working party of the 2005 Montreal World Congress of Gastroenterology. Can J Gastroenterol. 2005;19:5a-36a.

13. Harvey RF, Bradshaw JM. A simple index of Crohn's-disease activity. Lancet (London, England). 1980;1:514.

14. Ananthakrishnan AN, McGinley EL, Binion DG. Excess hospitalisation burden associated with Clostridium difficile in patients with inflammatory bowel disease. Gut. 2008;57:205-210.

15. Issa M, Vijayapal A, Graham MB, et al. Impact of Clostridium difficile on inflammatory bowel disease. Clin Gastroenterol Hepatol Off Clin Pract J Am Gastroenterol Assoc. 2007;5:345-351.

16. Rodemann JF, Dubberke ER, Reske KA, Seo DH, Stone CD. Incidence of Clostridium difficile infection in inflammatory bowel disease. Clin Gastroenterol Hepatol Off Clin Pract J Am Gastroenterol Assoc. 2007;5:339-344.

17. Joshi NM, Marks IH, Crowson R, Ball D, Rampton DS. Incidence and outcome of Clostridium difficile infection in hospitalized patients with inflammatory bowel disease in the UK. J Crohn's Colitis. 2017;11:70-76.
18. Goodhand JR, Alazawi W, Rampton DS. Systematic review: Clostridium difficile and inflammatory bowel disease. Aliment Pharmacol Ther. 2011;33:428-441.

19. Ben-Horin S, Margalit M, Bossuyt P, et al. Prevalence and clinical impact of endoscopic pseudomembranes in patients with inflammatory bowel disease and Clostridium difficile infection. J Crohn's Colitis. 2010;4:194-198.

20. van den Berg RJ, Bruijnesteijn van Coppenraet LS, Gerritsen HJ, Endtz HP, van der Vorm ER, Kuijper EJ. Prospective multicenter evaluation of a new immunoassay and real-time PCR for rapid diagnosis of Clostridium difficile-associated diarrhea in hospitalized patients. J Clin Microbiol. 2005;43:5338-5340.

21. van den Berg RJ, Vaessen N, Endtz HP, Schulin T, van der Vorm ER, Kuijper EJ. Evaluation of real-time PCR and conventional diagnostic methods for the detection of Clostridium difficileassociated diarrhoea in a prospective multicentre study. J Clin Microbiol. 2007;56:36-42.

22. Schneeweiss S, Korzenik J, Solomon DH, Canning C, Lee J, Bressler B. Infliximab and other immunomodulating drugs in patients with inflammatory bowel disease and the risk of serious bacterial infections. Aliment Pharmacol Ther. 2009;30:253-264.

23. Ananthakrishnan AN, Cagan A, Gainer VS, et al. Higher plasma vitamin $\mathrm{D}$ is associated with reduced risk of Clostridium difficile infection in patients with inflammatory bowel diseases. Aliment Pharmacol Ther. 2014;39:1136-1142.

24. Vandamme D, Landuyt B, Luyten W, Schoofs L. A comprehensive summary of LL-37, the factotum human cathelicidin peptide. Cell Immunol. 2012;280:22-35.

25. Hing TC, Ho S, Shih DQ, et al. The antimicrobial peptide cathelicidin modulates Clostridium difficile-associated colitis and toxin A-mediated enteritis in mice. Gut. 2013;62:1295-1305.

26. Kariv R, Navaneethan U, Venkatesh PG, Lopez R, Shen B. Impact of Clostridium difficile infection in patients with ulcerative colitis. J Crohn's Colitis. 2011;5:34-40.

27. McCurdy JD, Enders FT, Khanna S, et al. Increased rates of Clostridium difficile infection and poor outcomes in patients with IBD with cytomegalovirus. Inflamm Bowel Dis. 2016;22:2688-2693.

28. Chan KS, Lee WY, Yu WL. Coexisting cytomegalovirus infection in immunocompetent patients with Clostridium difficile colitis. $J$ Microbiol Immunol Infect. 2016;49:829-836. 